\title{
RAPID COMMUNICATION
}

\section{Central mechanisms in burning mouth syndrome involving the olfactory nerve: a preliminary study}

\author{
Mariana Siviero,' Manoel Jacobsen Teixeira," José Tadeu Tesseroli de Siqueira,"' Sílvia Regina Dowgan \\ Tesseroli de Siqueiralv
}

'Orofacial Pain Team, Faculdade de Medicina da Universidade de Sao Paulo, Brazil. "Neurology Department, Faculdade de Medicina da Universidade de Sao Paulo, Brazil. "' Head of the Orofacial Pain Team, Dentistry Division, Faculdade de Medicina da Universidade de Sao Paulo, Brazil. IV School of Arts, Science and Humanities, Universidade de Sao Paulo, Brazil.

Email: silviadowgan@hotmail.com

Tel.: 551191842878

\section{INTRODUCTION}

Burning mouth syndrome (BMS) is characterized by a continuous sensation of burning or heat in the oral cavity, mainly on the tongue, palate and/or gingiva ${ }^{1-3}$, in the absence of a primary cause ${ }^{4-5}$. Systemic diseases, such as diabetes mellitus or anemia, must be ruled out ${ }^{3}$. It is most common among postmenopausal women and causes intense discomfort and suffering.

There is no defined etiology for BMS other than precipitating causative factors, and it is still considered idiopathic. One of the most widely accepted theories is that the partial or total loss of chorda tympani (facial) nerve function disinhibits the trigeminal nerve, resulting in pain along trigeminal pathways, as both taste and pain systems are regulated by interneurons of the central nervous system (CNS) ${ }^{6-8}$. This theory is based on evidence of neuropathic mechanisms ${ }^{9-10}$, including the loss of small fibers in oral tissues ${ }^{11}$, salivary and somatosensory abnormalities ${ }^{8-10,12-14}$, reduced corneal reflexes 15 , and peripheral nerve degeneration ${ }^{11-16}$. Despite the known interaction between smell and taste ${ }^{17}$, we found no studies that investigated it in relation to BMS.

Thus, the objective of this preliminary study was to determine tactile, pain, thermal, gustative and olfactory thresholds in a group of patients with BMS as compared with controls.

\section{METHODS}

This research was approved by the Ethics Committee of Hospital das Clinicas, Medical School, University of Sao Paulo (HC-FMUSP), and all patients provided informed consent. Twenty consecutive patients with BMS, diagnosed according to the International Association for the Study of Pain (IASP) criteria ${ }^{18}$, were evaluated by the HC-FMUSP orofacial pain team between August 2007 and January 2008 and then compared with 30 normal subjects. All patients had BMS for more than 3 years and had no oral infections or

Copyright (c) 2011 CLINICS - This is an Open Access article distributed under the terms of the Creative Commons Attribution Non-Commercial License (http:// creativecommons.org/licenses/by-nc/3.0/) which permits unrestricted noncommercial use, distribution, and reproduction in any medium, provided the original work is properly cited. other lesions and no diseases included in the exclusion criteria.

Inclusion criteria: The study included 20 patients newly diagnosed with BMS who had not begun pharmacological treatment and 30 healthy controls with no complaint of facial or intraoral pain within the last 6 months who were consecutively selected from patients receiving dental treatment at the Dentistry Division of the hospital.

Exclusion criteria (for patients and controls): Exclusion criteria included Sjögren syndrome, rheumatological diseases (i.e., fibromyalgia and rheumatoid arthritis), diabetes, anemia, hyper- or hypothyroidism, generalized pain, and history of surgery in the facial/oral region. The patients and controls underwent a systematized evaluation by the hospital's general physician to investigate the presence of systemic diseases. In addition to the clinical exam, a hematological evaluation of thyroid hormones, glycemia, rheumatoid factors, including reactive $C$ protein and hemosedimentation velocity, and hemogram values was performed.

All subjects underwent a standardized superficial facial sensibility protocol applied to distinct areas of the face (bilateral trigeminal branches) and oral mucosa (superior and inferior arches) ${ }^{19}$ in the following order.

(1) Thermal sensibility (using an electrical device designed at the Functional Neurosurgery Division of HC-FMUSP) at a temperature range between $0{ }^{\circ} \mathrm{C}$ and $50^{\circ} \mathrm{C}$.

(2) Mechanical/tactile sensibility (using microfilaments from von Frey) ranging from $0.1 \mathrm{~g} / \mathrm{mm} 2$ to $10.0 \mathrm{~g} / \mathrm{mm} 2$.

(3) Pain sensibility/superficial algometry (using Micromar $^{\circledR}$, Diadema, São Paulo, Brazil).

Each thermal and mechanical stimulus was applied three times, and the threshold was established when the subject recognized at least two of the three applications. If this did not happen, the next stimulus in crescent order would be applied to avoid a tolerance effect. Algometry was performed with a superficial device and a disposable $0.7 \times 15-\mathrm{mm}$ needle. The ophthalmic branch (V1) was evaluated $1 \mathrm{~cm}$ above the eyebrow, and the maxillary branch (V2) was evaluated $1 \mathrm{~cm}$ to the side of the nose wing. Finally, the mandibular branch (V3) was evaluated $1 \mathrm{~cm}$ below the angle of the lips. 
Table 1 - Age and gender of BMS patients and controls $(\mathrm{N}=50)$.

\begin{tabular}{lcc}
\hline Groups & $\begin{array}{c}\text { Age ( } \pm \text { standard } \\
\text { deviation) } P=0.0033\end{array}$ & Gender (female) \\
\hline BMS & $60.95( \pm 12.21)$ & $16(80.0 \%)$ \\
CG & $68.86( \pm 9.79)$ & $10(33.3 \%)$ \\
\hline
\end{tabular}

BMS: Burning mouth syndrome; CG: Control group.

(4) Gustative thresholds were set according to the following molar concentrations ${ }^{20-22}$.

Sweet (glucose): $0.01 ; 0.032 ; 0.1 ; 0.32 ; 1.0$.

Sour (citric acid): $0.01 ; 0.032 ; 0.1 ; 0.32 ; 1.0$.

Salty (sodium chlorate): $0.01 ; 0.032 ; 0.1 ; 0.32 ; 1.0$.

Bitter (urea): $0.01 ; 0.032 ; 0.1 ; 0.32 ; 1.0$.

A single drop of each concentration was applied and swallowed by the patient; the results were compared to results from a single drop of distilled water. When the stimulus was not perceived, the next concentration was applied. The patient's mouth was washed with distilled water between different tastes.

(5) Olfactory threshold with isopropanol solutions (9.9; 15; 23.3; 32; 48; 53; 70\%) $23-24$. Each concentration was offered to the patient along with a bottle of water, and the patient was asked to choose the bottle containing the substance three times. The threshold was established when the patient correctly chose all three times. If the patient chose incorrectly, the next concentration was offered along with a bottle of water.

All subjects were evaluated in the sitting position, with the head resting on a flat surface and the Frankfurt line parallel to the ground. All evaluations took place at the same time of day (between 1 and $4 \mathrm{pm}$ ) in a silent room with acoustic protection on the walls and with the door closed. Only the patient and the researcher were in the room during evaluations. All patients were evaluated by the same researcher. The subjects received the same instructions after being positioned, which were to keep their eyes closed during the exam and to identify and report whether they felt the stimuli being applied to the face (by saying "yes" or "no") and what they felt (by naming the stimulus). Only the researcher knew the order in which the stimuli would be presented. Finally, all findings were tabulated and statistically analyzed.

\section{Statistical analysis}

For age and algometry, we used the one-factor ANOVA and Tukey's test. The Kruskall-Wallis test was used to
Table 3 - Between-group comparison of the superficial algometry means for all trigeminal branches. Thresholds at V1 and V2 $(\mathrm{N}=50)$ were higher.

\begin{tabular}{llll}
\hline & V1 $(p=0.289)$ & V2 $(p=0.132)$ & V3 $(p=0.143)$ \\
\hline$B M S$ & $31.900 \pm 20.83^{*}$ & $28.067 \pm 9.36 *$ & $25.067 \pm 8.93$ \\
$C G$ & $24.733 \pm 9.73$ & $23.000 \pm 12.50$ & $22.350 \pm 7.88$ \\
\hline
\end{tabular}

*One-factor ANOVA and Tukey's test $(p<0.05)$

V1: Ophthalmic branch; V2: Maxillary branch; V3: Mandibular branch; BMS: Burning mouth syndrome; CG: control group.

analyze facial and oral sensitivity. Finally, gustative and olfactory thresholds were evaluated with the KruskallWallis test followed by Dunns test. The level of significance was $\mathrm{p}<0.05$.

\section{RESULTS}

\section{Demographic characteristics}

The mean age of subjects was 60.95, and there were 16 women and 4 men in the BMS group. There was a significant age difference between groups (Table 1).

\section{Somatosensory findings}

There were no between-group differences in the somatosensory results for the ophthalmic branch, and similar cold thresholds were noted between the groups. The BMS patients had higher tactile thresholds at the maxillary branch $(p=0.001)$ and higher warm thresholds at the maxillary $(\mathrm{p}=0.032)$ and mandibular $(\mathrm{p}=0.001)$ branches (Table 2). The BMS patients had higher pain thresholds at the ophthalmic and maxillary branches $(p<0.05)$ (Table 3$)$. There were no intraoral sensibility differences between the studied groups $(\mathrm{p}=0.87)$.

\section{Gustative evaluation}

The gustative evaluation showed significant differences in all basic tastes (sweet $p<0.001$; salty $p=0.004$; sour $p=0.001$; bitter $p=0.001$ ). The BMS patients had higher salty, sweet and bitter thresholds but lower sour thresholds (Figure 1). Neither group exhibited difficulties with taste identification.

\section{Olfactory evaluation}

The BMS patients had higher olfactory thresholds (Figure 2).

\section{DISCUSSION}

This study presents evidence that supports the theory that the neuropathic mechanisms underlying BMS involve the somatosensory, gustative and olfactory pathways. To our

Table 2 - Between-group comparison of superficial sensibility in all modalities (cold, warm, and tactile) given the three trigeminal branches. Thresholds for the warm (V2 and V3) and tactile (V2) modalities were higher ( $N=50)$.

\begin{tabular}{|c|c|c|c|c|c|c|c|c|c|}
\hline \multirow[b]{2}{*}{ Modalities } & \multicolumn{3}{|c|}{ v1 } & \multicolumn{3}{|c|}{ V2 } & \multicolumn{3}{|c|}{ V3 } \\
\hline & BMS & CG & p & BMS & CG & $p$ & BMS & CG & $p$ \\
\hline Cold & $1.35 \pm 0.67$ & $1.27 \pm 0.45$ & 0.467 & $1.35 \pm 0.67$ & $1.10 \pm 0.31$ & 0.793 & $1.40 \pm 0.68$ & $1.27 \pm 0.45$ & 0.076 \\
\hline Warm & $1.45 \pm 1.76$ & $1.00 \pm 0.01$ & 0.097 & $1.40 \pm 0.75$ & $1.01 \pm 0.01$ & 0.032 * & $1.45 \pm 0.78$ & $1.00 \pm 0.01$ & 0.001 * \\
\hline Tactile & $1.40 \pm 0.50$ & $1.03 \pm 0.18$ & 0.064 & $2.40 \pm 0.50$ & $1.03 \pm 0.18$ & 0.001 * & $1.40 \pm 0.50$ & $1.03 \pm 0.18$ & 0.095 \\
\hline
\end{tabular}

*Kruskall-Wallis test

V1: Ophthalmic branch; V2: Maxillary branch; V3: Mandibular branch; BMS: Burning mouth syndrome; CG: Control group. 


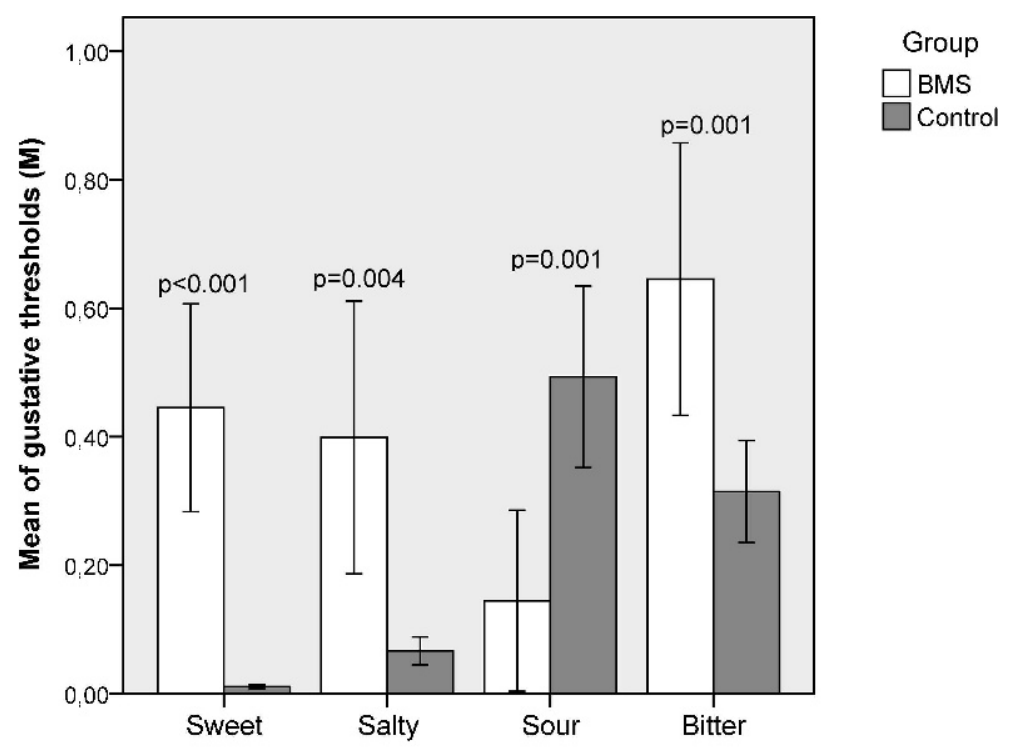

Error Bars: $95 \% \mathrm{Cl}$

(*) ANOVA 1 factor, PostHoc test: Tukey.

$\left.{ }^{* *}\right)$ BMS: Burning mouth syndrome; CG: Control group

Figure 1 - Compared to controls, the BMS patients had higher thresholds for sweet, salty and bitter tastes, but they had lower sour taste thresholds $(N=50)$.

knowledge, this is the first time the olfactory threshold of BMS patients has been investigated, and the findings show abnormalities in the trigeminal, gustatory and olfactory systems. Thus, these findings support the notion that central sensitization is involved in the physiopathology of this disease ${ }^{6-8}$. The pathophysiology is complex because of the

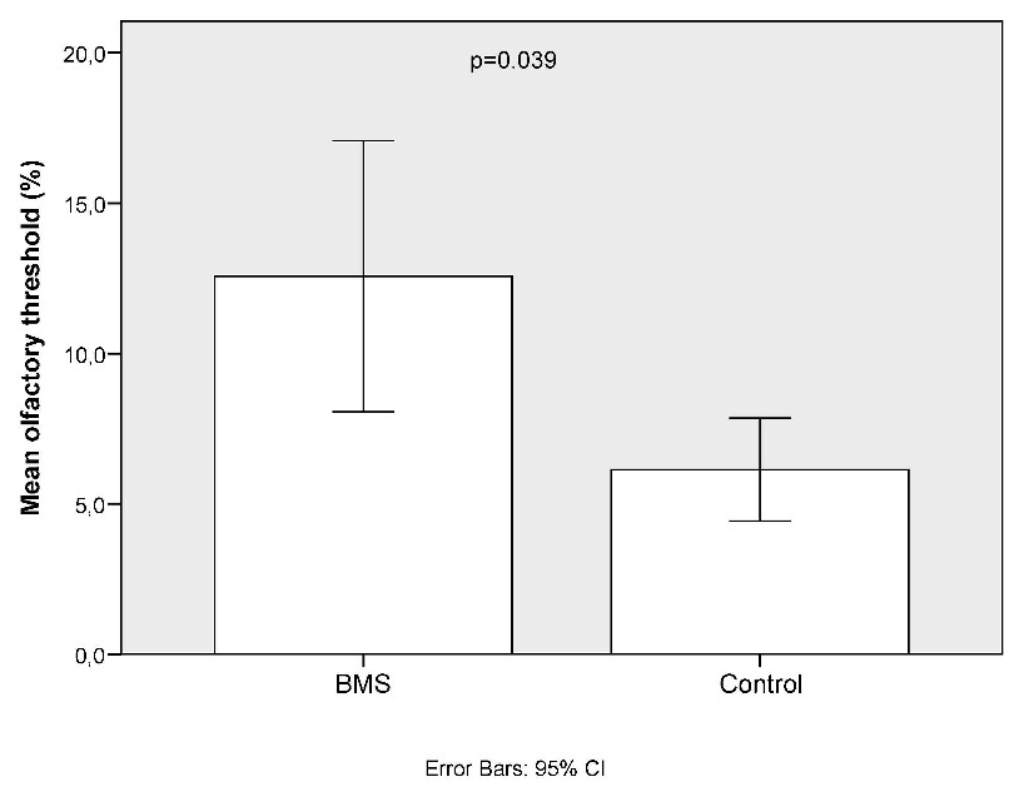

$\left(^{*}\right)$ ANOVA 1 factor. PostHoc test: Tukey.

$\left(^{* *}\right)$ BMS: Burning mouth syndrome; CG: Control group

Figure 2 - The BMS patients had higher olfactory thresholds than the controls $(N=5)$. 
overlapping of cortical areas that receive afferents with trigeminal and gustative inputs ${ }^{25}$. Furthermore, taste perception includes olfaction, and olfaction also requires somatosensory input ${ }^{26}$. These three sensory systems (i.e., trigeminal, gustatory and olfactory) show abnormal interactions in patients with BMS.

Our results are similar to those of previous studies that show decreased somatosensory perception in BMS patients, including higher tactile and thermal thresholds in all trigeminal branches $8,9,12$, higher taste thresholds $10,13,14$ and a delay in the blink reflex ${ }^{15}$. Thermal abnormalities in the orofacial region that only pertain to the perception of warmth might be associated with the burning sensation these patients describe, and it has been reported that abnormal functioning of the warmth-perceiving pathways can induce burning pain sensations ${ }^{27}$. It is possible that in BMS, there is a malfunction in warmth detection that leads to a pain sensation and, when it becomes chronic, induces other somatosensory, gustative and olfactory disturbances through central mechanisms, including neuroplasticity at the cortical areas responsible for sensory interaction 26 . Abnormal taste has been described as a consequence of the loss of warmth detection ${ }^{27}$. In this sense, BMS could be described as a phantom sensation of heat on the tongue.

In the gustative evaluation, the sweet, salty and bitter tastes had higher thresholds, but the sour taste had lower thresholds. Sour is the taste that involves the activity of $\mathrm{H}+$ ions directly through channels in the receptor membranes, which also can activate small pain fibers. In addition to peripheral nerve degeneration 11,16, a more sensitive perception of acids (for taste and pain) could be a peripheral mechanism of BMS.

A limitation in this study is the small sample size. Larger studies are necessary to confirm the reported results. Although there was an age difference between the groups, the implications of this difference are controversial, especially for gustation and olfaction, which apparently does not differ by age or gender ${ }^{28}$.

In conclusion, this preliminary study shows evidence of abnormal thresholds for pain, tactile, warmth perception, olfaction and gustation. Given these results and previous results in the literature, we propose a phantom heat sensation involving central pathophysiology as a mechanism in BMS.

FINANCIAL SUPPORT: FAPESP - Research Foundation of the State Of São Paulo, FAPESP, 2007/04156-4

\section{REFERENCES}

1. Grushka M, Sessle BJ. Burning mouth syndrome. Dental Clinics North America. 1991;35:171-84.

2. Nasri C, Siqueira JTT. Síndrome da Ardência Bucal. In: Siqueira JTT, Teixeira MJ. Dor Orofacial: diagnóstico, terapêutica e qualidade de vida. Curitiba: Ed Maio, pp.525-34,2001.

3. Patton LL, Siegel MA, Benoliel R, De Laat A. Management of burning mouth syndrome: systematic review and management recommendations. Oral Surgery Oral Medicine Oral Pathoogyl Oral Radiology Endodontics. 2007;103 Suppl:S39.e1-13.
4. Ship JA, Grushka M, Lipton JA, Mott AE, Sessle BJ, Dionne RA. Burning mouth syndrome: an update. J Am Dent Assoc. 195;126: 842-53.

5. Nasri C, Teixeira MJ, Okada M, Formigoni G, Heir G, Siqueira JT. Burning mouth complaints: clinical characteristics of a Brazilian sample. Clinics. 2007;62:561-6, doi: 10.1590/S1807-59322007000500005.

6. Bartoshuk LM, Grushka M, Duffy VB, Fast K, Lucchina L, Prutkin J, et al. Burning mouth syndrome: damage to $\mathrm{CN}$ VII and pain phantoms in $\mathrm{CN}$ V. Chemical senses. 1999;24:609.

7. Bergdahl M, Bergdahl J. Burning mouth syndrome: prevalence and associated factors. J Oral Pathol Med. 1999;28:350-4, doi: 10.1111/j.16000714.1999.tb02052.x.

8. Grushka M, Epstein JB, Gorsky M. Burning mouth syndrome and other oral sensory disorders: a unifying hypothesis. Pain Res Man. 2003;8: 133-5.

9. Forssell H, Jääskeläinen S, Tenovuo O, Hinkka S. Sensory dysfunction in burning mouth syndrome. Pain. 2002;99:41-7, doi: 10.1016/S03043959(02)00052-0.

10. Femiano F. Damage to taste system and oral pain: burning mouth syndrome. Minerva Stomatol. 2004;53:471-8.

11. Yilmaz Z, Renton T, Yiangou Y, Zakrzewska J, Chessell IP, Bountra C, et al. Burning mouth syndrome as a trigeminal small fibre neuropathy: Increased warm and capsaicin receptor TRPV1 in nerve fibres correlates with pain score. J Clin Neurosci. 2007;14:864-71, doi: 10.1016/j.jocn.2006. 09.002 .

12. Svensson P, Bjerring P, Arendt-Nielsen L, Kaaber S. Sensory and pain thresholds to orofacial argon laser stimulation in patients with chronic burning mouth syndrome. Clin J Pain. 1993;9:207-15, doi: 10.1097/ 00002508-199309000-00009.

13. Formaker BK, Frank ME. (Taste function in patients with oral burning. Chem senses. 2000;25:575-81, doi: 10.1093/chemse/25.5.575.

14. Femiano F, Lanza A, Buonaiuto C, Gombos F, Cirillo N. Burning mouth disorder (BMD) and taste: a hypothesis. Medical Oral Pathology Oral Cir Bucal. 2008;13:E470-4.

15. Jääskeläinen SK, Forssell H, Tenovuo O. Abnormalities of the blink reflex in burning mouth syndrome. Pain. 1997;73:455-60, doi: 10.1016/S03043959(97)00140-1.

16. Eliav E, Kamran B, Schaham R, Czerninski R, Gracely RH, Benoliel R. Evidence of chorda tympani dysfunction in patients with burning mouth syndrome. J Am Dent Assoc. 2007;138:628-33.

17. Rawson N.E. Olfactory loss in aging. Science Aging Knowledge Environment. 2006;5:pe6, doi: 10.1126/sageke.2006.5.pe6.

18. Merskey H, Bogduk N. Classification of chronic pain: descriptions of chronic pain syndromes and definitions of pain terms. Seattle, WA: IASP Press, 1994.

19. Siviero M, Teixeira MJ, de Siqueira JT, Siqueira SR. Somesthetic, gustatory, olfactory function and salivary flow in patients with neuropathic trigeminal pain. Oral Dis. 2010;16:482-7, doi: 10.1111/j. 1601-0825.2010.01660.x.

20. Kamath S, Booth P, Lad TE, Kohrs MB, McGuire WP. Taste thresholds of patients with cancer of the esophagus. Cancer. 1983; 52:386-9, doi: 10 . 1002/1097-0142(19830715)52:2<386::AID-CNCR2820520233>3.0.CO;2-8.

21. Bartoshuk L. Clinical evaluation of the sense of taste. Ear Nose Throat J. 1989;68:331-7.

22. Perros P, MacFarlane TW, Cunsell C, Frier BM. Altered taste sensation in newly-diagnosed NIDDM. Diabetes Care. 1996;19:768-70, doi: 10.2337/ diacare.19.7.768.

23. Cain WS. Testing olfaction in a clinical setting. Ear Nose Throat J. 1989;68:316-28.

24. Davidson TM, Murphy C. Rapid clinical evaluation of anosmia. Arch Otolaryngology Head Neck Surg. 1997;123:591-4.

25. Ohla K, Toepel U, le Coutre J, Hudry J. Electrical neuroimaging reveals intensity-dependent activation of human cortical gustatory and somatosensory areas by electric taste. Biol Psychol 2010. In press.

26. Sperdin HF, Cappe C, Murray MM. The behavioral relevance of multisensory neural response interactions. Front Neurosci 2010;4:9.

27. Bouhassira D, Kern D, Rouaud J, Pelle-Lancien E, Morain F. Investigation of the paradoxical painful sensation ('illusion of pain') produced by a thermal grill. Pain. 2005;114:160-7, doi: 10.1016/j.pain.2004.12.014.

28. Henkin RI, Velicu I, Papathanassiu A. cAMP and cGMP in human parotid saliva: relationships to taste and smell dysfunction, gender, and age. Am J Med Sci. 2007;334:431-40, doi: 10.1097/MAJ. 0b013e3180de4d97. 